\title{
Presentación del proyecto de investigación: "La enseñanza y el aprendizaje de las Ciencias Sociales y la Historia en la cultura digital: dimensiones epistemológica y metodológica"
}

Introduction to the research project: "Teaching and learning Social Sciences and History in digital culture: Epistemological and methodological dimensions"

Graciela Funes*

\section{RESUMEN}

El proyecto de investigación "La enseñanza y el aprendizaje de las Ciencias Sociales y la Historia en la cultura digital" que desarrollamos en la actualidad tiene por objetivo conocer como enseñan y aprenden ciencias sociales e historia en contextos de cultura digital, algunas aulas de educación infantil, elemental y secundaria. Se desarrolla en escuelas públicas de la Nord Patagonia Argentina y reconoce la modalidad cualitativa de la investigación educativa. En este artículo desarrollaré las decisiones epistemológicas y metodológicas de la investigación en curso.

Palabras claves: ciencias sociales; didáctica; cultura digital.

\section{Abstract}

The research project "Teaching and learning Social Sciences and History in digital culture" that we develop nowadays aims to know how Social Sciences and History have been taught and learned in the context of digital culture in some child classrooms, as well as in elementary and secondary schools. The project takes place in public schools in the Nord Patagonia Argentina and recognizes the qualitative mode of educational research. In this article I will develop the epistemological and methodological decisions of the ongoing investigation.

Keywords: social sciences; didactic; digital culture.

\footnotetext{
* Profesora en Historia. Magister en Didáctica, Doctora en Educación. Investigadora y Directora de la Carrera de Posgrado Especialización en Didáctica de las Ciencias Sociales, Universidad Nacional del Comahue. Neuquén, Argentina. agfunes@hotmail.com
} 


\section{InVESTIGACIÓN EN DidÁCTICA DE}

\section{las Ciencias Sociales e Historia}

Esta investigación en Didáctica de las Ciencias Sociales la desarrollamos con algunas herramientas del oficio de historiar. La construcción de los problemas que investigamos son preocupaciones que parten del presente y que reconoce los desafíos que el siglo XXI imprime a nuestra cotidianidad y a las nuevas generaciones, esa reflexión es un ejercicio eminentemente investigativo. Desde este presente interesa abrir pasados para reconocerlos en el entrecruzamiento de futuros, en ese vaivén entre futuros pasados interesa estudiar algunos cambios con la intencionalidad de describirlos y explicarlos para crear sentido a la investigación.

La investigación didáctica es una práctica que enlaza un problema específico de investigación, de formación de formadores y de enseñanza de contenidos relativos al conocimiento social, ninguno de estos ámbitos puede circunscribirse con anterioridad a un examen de su relación con los otros dos. Dice Themines (2009) que resulta imposible presentar un cuadro sintético de cómo los investigadores-formadores abordan esas relaciones porque investigar, formar y enseñar ciencias sociales constituye una región fronteriza que busca y promueve enlaces, conexiones, articulaciones entre: trazados disciplinares; certidumbres, azares y evidencias; modos de dudar; formas de conocer registradas en las distintas formaciones académicas.

Cuando hacemos investigación educativa, buscamos conocer problemas fundados en la realidad misma de profesoras y profesores y del estudiantado en contextos y momentos específicos, instalar nuevas o viejas preguntas en un espacio bisagra entre diseños globales e historias locales, ya que a la hora de enseñar y aprender historia y ciencias sociales en cualquier lugar de este pequeño mundo no hay nada nuevo y todo es muy nuevo simultáneamente ( $\mathrm{Pa}$ gès, 2013).

La tarea de las disciplinas sociales es conocer y pensar y en esa conjunción nos encontramos con la práctica de investigar en lugares difíciles como son las aulas y las escuelas, que son antes que nada difíciles de describir y pensar (Bourdieu, 2013) y para hacerlo las imágenes simplistas y unilaterales tienen que ser reemplazadas por representaciones complejas y múltiples, fundadas en la expresión de las mismas realidades, en discursos diferentes, a veces inconciliables 
posibilitando la pluralidad de miradas del mundo social para explicar comprensivamente una gran parte de lo que sucede en ese mundo. Estar atentos a abandonar el punto de vista único, central y dominante en beneficio de la pluralidad de puntos de vista coexistentes, que permitan poner en perspectivas miradas, palabras, acciones para percibir y comprender las prácticas investigativas, de formación y de enseñanza.

Interesados en describir y pensar la enseñanza y el aprendizaje de las ciencias sociales y la historia en la cultura digital para construir conocimiento sustantivo que aporte a la formación de profesores en ciencias sociales e historia y a su enseñanza en los tres niveles educativos, desarrollamos esta investigación en la Universidad Nacional del Comahue durante 2013-2016.

\section{UN PROYECTO DE INVESTIGACIÓN EN DidÁCTICA:}

\section{LA ENSEÑAnZay El APREndizaje de las Ciencias Sociales Y LA HisTORIA EN LA CULTURA DIGITAL}

En esa universidad enseñamos a enseñar historia y ciencias sociales a los estudiantes de los profesorados en Nivel Inicial y Primario y en Historia y desarrollamos investigación educativa. En 2013, comenzamos éste proyecto motivado por las discusiones sobre los cambios en las formas de enseñar y de aprender con tecnologías, sabemos que el acceso y el uso son desiguales y si bien las políticas públicas dotaron a las escuelas de materiales tecnológicos, no siempre se utilizan. Por otro lado, nos interesa saber cómo se ubican las tecnologías y agencias culturales en relación a la escuela y al aula de ciencias sociales e historia.

En las aulas de historia y ciencias sociales circulan materiales y fuentes de información múltiple y variada a disposición de profesores y estudiantes. Materiales escritos: editorializados, no escolarizados y periodísticos; videos y programas televisivos, CD-ROMs, multimedias e internet; también se accede fácilmente a diversas las fuentes orales. Frente a esta diversidad estamos interesados en comprender las enseñanzas y aprendizajes en ciencias sociales e historia en el marco de la cultura digital, para generar propuestas de intervención en la formación docente inicial y permanente, por ellos nos preguntamos: 
- ¿Qué significado de las ciencias sociales y de la historia validan estudiantes y profesores?

- ¿Qué lugar le asignan a las herramientas/ máquinas en el proceso del enseñar y del aprender?

- ¿Posibilitan intercambios e interacciones docentes/estudiantes más fluidas?

- ¿Qué finalidades y sentidos orientan la enseñanza y el aprendizaje?

- ¿Potencian la formación del pensamiento crítico?

Los objetivos de la investigación aspiran a:

- Analizar críticamente la red de vínculos entre medio de comunicación, nuevas tecnologías, y conocimientos sociales enseñados a fin de construir dispositivos pedagógicos didácticos para el aprendizaje y la enseñanza de las ciencias sociales y de la historia en instituciones educativas de los tres niveles de enseñanza en Río Negro y Neuquén.

- Analizar cómo las nuevas herramientas/máquinas transforman la experiencia educativa en el aula de ciencias sociales y de historia.

- Examinar si la digitalización ha modificado las relaciones epistemológicas en la construcción del conocimiento social enseñado.

- Analizar la relación dialéctica forma-contenido de la enseñanza de las ciencias sociales y la historia que despliegan docentes de escuelas públicas neuquina y rionegrina.

- Establecer las relaciones entre enseñanza de las ciencias sociales e historia y la formación del pensamiento crítico, conciencia histórica, identidades.

- Construir conocimiento sustantivo que aporte a la retroalimentación de la formación de profesores en ciencias sociales e historia y a su enseñanza en los tres niveles de enseñanza en el marco de la ineludible vinculación investigación - docencia - extensión.

Es un estudio cualitativo que de alguna manera representa tanto investigar como "enseñar" a investigar a profesoras y profesores que intervienen en el proceso, es un trabajo colaborativo y solidario entre docentes y se constituye 
en un espacio habitado para coproducir formaciones docentes iniciales y permanentes en torno a cocimientos y prácticas del conocimiento social e histórico enseñado. Los resultados de la investigación ansían contribuir a la reflexión sobre la pertinencia conceptual y metodológica de la investigación en didáctica de las ciencias sociales e historia, a la elaboración de estrategias de intervención en la práctica de educativa, a constituir un espacio habitado para pensar la formación docente inicial y continuada en torno a conocimientos y prácticas del conocimiento social e histórico y a su enseñanza en los tres niveles educativos.

\section{PoRque Y COMO INVESTIGAR LA ENSEÑANZA Y EL APRENDIZAJE DE} LAS CIENCIAS SOCIALES Y DE LA HISTORIA EN LA CULTURA DIGITAL

Porque es un problema del presente y en él, lo digital es una nota distintiva de la cultura contemporánea que está siendo estudiada por investigadores de diversos países latinoamericanos, ${ }^{1}$ lo que posibilitará más adelante entender las claves del mismo en perspectiva comparada.

La cultura digital demanda de las personas que sepan utilizar las tecnologías de manera crítica y puedan "operar" sobre la nueva racionalidad que esta le imprime. Nos interesa investigar la enseñanza y el aprendizaje de la historia y las ciencias sociales en la cultura digital como un problema del presente, al que miramos en clave estructural y reconociendo la dinámica del cambio. Estamos interesados en conocer como estudiantado y profesorado experimentan la cultura digital, como acceden y usan sus herramientas y a partir de esas experiencias buscar patrones y referencias que nos indiquen como y para que se conoce, en que se cree, porque lo digital es ante todo cultural e histórico (Doueihi, 2010). La cultura digital, está inmersa en un proceso de cambio que por su propia dinámica necesita sumar la flexibilidad de una mentalidad abierta para cambiar los cambios.

La indagación la llevamos adelante en ciudades de la Nord Patagonia Argentina, por ello es una reflexión construida desde un espacio geográfico y desde localizaciones epistemológicas que enriquecen la producción en tanto posibilita pensar en las construcciones simbólicas que se juegan a la hora de enseñar y aprender conocimientos sociales, para ser más precisos nos interesan las maneras locales de conocer (Grosso, 2012) atravesadas por las políticas y 
tecnologías nacionales y globales. Dice Walter Mignolo (2003) que el conocimiento no es abstracto ni des-localizado, es más bien todo lo contrario y el gran tema del siglo XXI para América Latina será la doble traducción y la interculturalidad. Conocer modos de enseñar y aprender en clave local, desarticula miradas homogeneizadoras, reconoce las múltiples mediaciones que se producen en las aulas y que dan cuenta de traducciones, interculturalidades, polifonías de voces, creencias, estereotipos y autorías.

Enseñar y aprender ciencias sociales e historia en la cultura digital es una temática que se puede leer desde las premisas de la historia cultural, ya que esta centra la atención en los lenguajes, las representaciones y las prácticas (Chartier, 2007; 2007a). Con los modelos de la antropología y de la crítica literaria se leen textos e imágenes para comprender las acciones individuales y colectivas en sus significaciones simbólicas. Una lectura cultural de textos e imágenes, nos recuerda que hay formas de leer, escuchar, ver, participar y que esa diversidad da cuenta de la construcción de su significación. Una lectura cultural de lo que acontece con la tecnología y la digitalización en escuelas de Río Negro y Neuquén es lo que interesa a este proyecto y por ello centramos la mirada en la articulación entre prácticas y discursos. Sabemos que las disciplinas sociales son disciplinas textuales y que la textualidad electrónica modifica la organización de las argumentaciones, que los autores ya no deciden los límites de un tema, sino que lo hacen los lectores con sus clics a través de las capas de enlaces, que Internet significa asumir una nueva estrategia para el aprendizaje, con una filosofía de: "inclúyelo todo; fíltralo al final". Internet es un mundo con límites porosos en el que la autoridad cambia constantemente: siempre hay algo más que se acaba de decir sobre lo dicho. Escrituras e imágenes; instantes, inmediatez y larga duración; comunicación, información y redes sin límites multiplica los ojos y las voces para ver el mundo de otras maneras.

Estudiantado, profesorado e investigadoras/es buscamos conceptualizar desde la propia experiencia la relación con la cultura digital en la enseñanza y el aprendizaje ya que esta impacta en la identidad, privacidad e imaginación de los y las jóvenes (Gardner; Davis, 2014) y que la niñez vive una experiencia cultural distinta con nuevas maneras de sentir, escuchar y de ver (Morduchowicz, 2014).

Este estudio reconoce la modalidad cualitativa y privilegia la metodología del estudio de casos que focaliza en la particularidad y complejidad de 
singularidades, tiene como finalidad la comprensión profunda de una realidad específica: profesoras y profesores neuquinos y rionegrinos junto a estudiantes en la cultura digital, para llegar a comprender las prácticas de la enseñanza y el aprendizaje de las ciencias sociales y la historia en los aspectos vinculados con la construcción e interacción del conocimiento, la simultaneidad en la circulación de la información, el lugar de los actores y el trabajo entre pares, los cambios en los procesos y ritmos de enseñanza y de aprendizajes, los tiempos, espacios y agrupamiento, la acción individual y colectiva de docentes y estudiantes, entre otros.

Seleccionamos los casos atendiendo a la diversidad y complejidad ${ }^{2} \mathrm{de}$ las situaciones de enseñanza del conocimiento social e histórico en el marco de la cultura digital a fin de analizar si se generan nuevos entornos de aprendizaje, si producen un fortalecimiento de la red de aprendizaje entre estudiantes, si posibilitan una ampliación de la tarea docente, si las relaciones dialécticas forma contenido potencian aprendizajes significativos, en fin nos interesa saber qué construcciones metodológicas circulan en la clase de ciencias sociales e historia. En la construcción de cada caso se diseñan e implementan enseñanzas colectivas y colaborativas (Bednarz; Lebuis; Poirier; Couture, 2001; Desgagné; Bednarz, 2005).

Disponemos, enhorabuena, de un importante caudal de experiencias ${ }^{3}$ que nos permiten objetivar esos cambios y prácticas y describir analíticamente el nuevo componente de este escenario epocal con tecnología digital y lo digital en las prácticas de la enseñanza. Cada caso se conforma a partir del trabajo participativo y colaborativo entre investigadores-docentes; docentes-investigadores habitando un lugar de co-investigación y de formación ya que, investigamos para formar y formamos para investigar (Funes; Jara; Salto, 2006), este encuadre participativo apunta a la construcción de conocimiento científico como instrumento emancipatorio y tiende a que el objeto de estudio devenga sujeto participante en esa construcción de conocimiento colectivo sobre su entorno cotidiano.

Interesa destacar que el estudio refiere a la experiencia de sujetos que enseñan y aprenden. La experiencia se genera en la vida material y las maneras en que una generación viviente elabora la experiencia, desafía toda predicción y escapa a toda definición estrecha de determinación. Las personas viven su experiencia bajo la forma de ideas, pensamientos, procedimientos y 
sentimientos que elaboran en las coordenadas de la cultura, en tanto normas, obligaciones y reciprocidades que han de ser interpretada como experiencia vivida y conocida que pone en evidencia valoraciones propias de involucramiento y compromiso de los sujetos que enseñan.

El registro de esta investigación en didáctica de las ciencias sociales, sus fundamentos teóricos- metodológicos muestran que experiencias, trayectorias $y$ artefactos culturales se constituyen en herramientas conceptuales que se articulan en la producción de enseñanzas y aprendizajes sociales relevantes. La identificación de situaciones pedagógicas complejas sean estas: institucionales, contextuales, sociales, historiográficas, didácticas, el tiempo para pensar y encontrar las mejores alternativas para dar lugar a aprendizajes donde tenga lugar la exploración y el descubrimiento, la creatividad y la sensibilidad, el pensamiento crítico, la actitud colaborativa y solidaria, orientan a suscitar el logro de autonomías profesorales y estudiantiles.

Analizar trayectorias docentes y estudiantiles para conocer y entender mejor a partir de la realidad experiencial de sus mundos vitales (Manen, 2003), requiere y exige al investigador ser reflexivo, intuitivo, sensible y constantemente abierto a experiencias y subjetividades que se ponen en juego en los relatos. Dice Leonor Arfuch (2007) que el surgimiento de los géneros autobiográfico es un fenómeno de civilización que sostiene la idea que es posible conocer, comprender, explicar, prever y hasta remediar situaciones a partir de las narrativas vivenciales y testimoniales de los sujetos identificados. El registro de las experiencias escolares en una herramienta imprescindible que permite a los educadores entrar en un diálogo riguroso y sistemático en las prácticas de la enseñanza.

Así mismo, la investigación adhiere a los principios deontológicos que guían la actividad profesional de los investigadores: respetar los derechos de todo investigado, tener su consentimiento y aceptación consciente y libre y usar la información para los fines previstos y conocidos por todos los involucrados.

\section{LAS FINALIDADES DEL ESTUDIO}

La transmisión de conocimientos no es la única función de la escuela, la creación y legitimación del saber evidencia una red de interacciones entre la 
escuela y el mundo cultural y social generando el conocimiento social escolar que tiene una naturaleza y una función específica. Sabemos que no hay una única manera de construir y organizar los contenidos de una disciplina, ni existe una única explicación de su validez, efectivamente el mundo de la disciplina es un mundo de ideas y de personas.

En tiempos de cambios es importante pensar cuál es el norte del acto de educar social e históricamente, en esta investigación sostenemos la perspectiva de educar para la emancipación y la igualdad (Rancière, 2003) y buscamos propiciar enseñanzas sociales situadas en contexto. Paulo Freire (1974) señala, nuestras relaciones con los educandos nos imponen el conocimiento de las condiciones concretas de su contexto, que los condiciona, conocer la realidad en la que viven es un deber de la práctica educativa: sin esto, no tenemos acceso a su modo de pensar y difícilmente podremos, entonces, percibir lo que saben y cómo lo saben. No existen temas o valores que no se puedan hablar en tal o cual área, se puede hablar de todo y de todo dar testimonio.

Buscamos conocer experiencias y trayectorias de historias enseñadas inclusivas (Funes, 2012) apartadas de miradas unívocas y de narrativas maestras (Carretero, 2007), que apunten a fundamentar y poner en acción finalidades formativas para una cultura múltiple, diversa y compartida en y para la reflexión y la acción social y política. Las finalidades cívicas y culturales de la enseñanza de la historia cobran vigencia para instancias de inclusión y pertenencia. Dice Cornelius Castoriadis (1996) que una sociedad será democrática si los sujetos son formados dentro, y a través, de una paideia democrática siendo este el objetivo central de las preocupaciones políticas. En tiempos de miradas tecnicistas de lo educativo y de lo político, interesa reafirmar que en este estudio buscamos repensar en la complejidad del carácter político del acto de educar (Frigerio; Diker, 2005). Para conocer el mundo sociocultural se requieren códigos interpretativos, los cambios producidos en lo últimos decenios revela la descomposición de las claves interpretativas, entonces un tema prioritario para la enseñanza de las ciencias sociales y de la historia es la socialización política y para ello se hace necesario repensar las coordenadas de interpretación de los mapas políticos y esa cartografía está atravesada por la cultura digital. Construir cartografías que nos ubiquen y señalen el camino 
para pensar, sentir y actuar, diseñando nuevas narrativas inclusivas de este tiempo conjugando la identidad y la memoria.

Buscamos conocer los cambios en las formas de enseñar y de aprender con tecnologías y nos hacemos la misma pregunta que Inés Dussel (2011) ¿Vino viejo en odres nuevos?

Muchas cuestiones deben matizarse: el problema del acceso habido cuenta que muchos niños y jóvenes no están en el mismo estándar; la expansión de la tecnología en el aula ¿para qué?, ¿cómo se usa? La brecha se desplaza del acceso al uso, hay usos más pobres y otros más complejos y ricos. Analizar críticamente una red de vínculos entre medio de comunicación, tecnologías, historias enseñadas es un objetivo de investigación. Repensar y resituar a los sujetos del aula de ciencias sociales e historia es otro desafío.

La alfabetización digital vehicula un imaginario social que pone en juego no sólo la dimensión virtual de las tecnologías, sino también determinados postulados y prejuicios religiosos, históricos y políticos. Éstos moldean la nueva cultura con fuerza más allá de las fronteras nacionales y culturales. Este orden social virtual está reivindicando una universalidad anclada en la supuesta neutralidad de la tecnología, pero esa universalidad, para su coherencia y su inteligibilidad, depende de la identidad digital. Queda claro que la cultura digital efectúa una transición política, sociológica y cultural.

Para finalizar nos importa decir que nuestra investigación no está interesada en pensar el problema investigativo en las virtualidades pedagógicas de las tecnologías (San Martín Alonso, 1995), en este problema prima la cultura tecnológica que privilegian el uso de las herramientas digitales, toda su apuesta está en la presencia de las mismas y no en la descripción y en el análisis de lo que sucede con, desde y a partir de ellas en las aulas

Tampoco nos interesa definirlo como la enseñanza y el aprendizaje en "nuevas tecnologías", porque el problema de la representación y la mediación didáctica con tecnologías son de larga data y en ella no sabríamos situar la novedad. Buscamos desde la racionalidad crítica, el desafío metodológico de partir de las sensaciones que sentimos frente a los objetos-máquinas para buscar descripciones reflexivas y expresivas que nos inviten a pensar holísticamente el difícil mundo social. 


\section{REFERENCIAS}

ARFUCH, Leonor. El espacio biográfico: dilemas de la subjetividad contemporánea. Buenos Aires: Fondo de Cultura Económica, 2007.

ARRUDA, Eucidio. Cultura e ensino de História na perspectiva das redes sociais e do ciberespaco. In: SILVA, Cristiani Bereta da; ZAMBONI, Ernesta. Ensino de História: memória e culturas. Curitiba: Ed. CRV, 2013. p.35-53.

BEDNARZ, Nadine; LEBUIS, Pierre; POIRIER, Louise; COUTURE, Christine. L'approche collaborative de recherche en éducation: un rapport nouveau à établir entre recherche et formation. Revue des sciences de l'éducation, v.27, n.1, p.33-64, 2001. Disponible en: http://id.erudit.org/iderudit/000305ar.

BOURDIEU, Pierre. La miseria del mundo. Buenos Aires: Fondo de Cultura Económica, 2013.

CARRETERO, Mario. Documentos de identidad: la construcción de la memoria histórica en un mundo global. Buenos Aires: Paidós, 2007.

CASTORIADIS, Cornelius. La democracia como procedimiento y como régimen. Iniciativa socialista, n.38, 1996.

CHARTIER, Roger. Existe una nueva historia cultural. In: GAYOL, S.; MADERO, M. Formas de historia cultural. Buenos Aires: Universidad Nacional de General Sarmiento; Prometeo, 2007. p.29-43. . La historia o la lectura del tiempo. España: Gedisa, 2007a.

DESGAGNÉ, Serge; BEDNARZ, Nadine. Médiation entre recherche et pratique en éducation: faire de la recherche "avec" plutôt que "sur" les praticiens. Revue des sciences de l'éducation, v.31, n.2, p.245-258, 2005. Disponible en: http://id.erudit. org/iderudit/012754ar.

DOUEIHI, Milad. La gran conversión digital. Buenos Aires: Fondo de Cultura Económica, 2010.

DUSSEL, Inés. Aprender y enseñar en la cultura digital. Buenos Aires: Documento Básico. Fundación Santillana, 2011.

La escuela y los nuevos medios digitales. Notas para pensar las relaciones con el saber en la era digital. In: AA.VV. La Educación Alterada: aproximaciones a la escuela del siglo XXI. Villa María, Córdoba: Universidad Nacional de Villa María (Eduvim); Salidas al mar ediciones, 2010. p.5-23.

FREIRE, Paulo. Concientización. Buenos Aires: Búsqueda, 1974.

FRIGERIO, Graciela; DIKER, Gabriela (Comp.) Educar: ese acto político. Buenos Aires: Editorial del estante, 2005.

FUNES, Graciela. Formación docente para la enseñanza de historias inclusivas. [On-line]. Cadernos de Pesquisa, Uberlândia: CDHIS, v.25, n.1, p.71-89, 2012. 
FUNES, Graciela; JARA, Miguel; SALTO, Víctor. La Historia Reciente, investigar para formar y enseñar. In: GOMEZ, Ernesto; NUÑEZ, María. Formar para investigar, investigar para formar en la didáctica de las ciencias sociales. Málaga: AUPDCS; Digarza, 2006. p.275-285.

GARDNER, Howard; DAVIES, Katie. La generación APP: cómo los jóvenes gestionan su identidad, su privacidad y su imaginación en el mundo digital. Buenos Aires: Paidós, 2014.

GROSSO, Jorge. Del socioanálisis a la semiopraxis de la gestión social del conocimiento: contranarrativas en la telaraña global. Colombia: Universidad del Cauca, 2012.

LAMAS, Ana María. Educación y nuevas tecnologías o de cómo enseñar a la generación net. Buenos Aires: San Pablo/Nuevo humanismo, 2012.

MANEN, Max. Investigación educativa y experiencia vivida. Barcelona: Idea Books, 2003.

MORDUCHOWICZ, Roxana. Los chicos y las pantallas: las respuestas que buscamos. Buenos Aires: Fondo de Cultura Económica, 2014.

PAGÈS, Joan. Enseñar historia en la Patagonia y en cualquier lugar de este pequeño mundo. In: FUNES, Graciela. Historias enseñadas recientes: utopías y prácticas. Neuquén: Educo, 2013. p.9-15.

RANCIÈRE, Jacques. El maestro ignorante. Barcelona: Laertes, 2003.

SAN MARTÍN ALONSO, Angel. De la "miseria" del método a la "grandeza" de las tecnologías. In: SANCHO, Juana; MILLÁN, Luis (Comp.) Hoy ya es mañana: tecnologías y educación: un diálogo necesario. Sevilla: Cuadernos de Cooperación Educativa, 6, 1995. p.75-92.

SERPA, Angelo. Lugar e mídia. São Paulo: Contexto, 2011.

THEMINES, Jean. Investigación y formación del profesorado en didáctica de la geografía: posibilidades e implicaciones de algunas investigaciones de las prácticas docentes en Francia. Enseñanza de las Ciencias Sociales - Revista de investigación, Barcelona: Universitat Autònoma de Barcelona (UAB) / Universitat de Barcelona (UB), n.8, p.13-25, 2009.

WALSH, Catherine. Las geopolíticas del conocimiento y la colonialidad del poder. Entrevista a Walter Mignolo. [On-line]. Polis Revista Latinoamericana, v.4, p.219, 2003. Disponible en: http://polis.revues.org/7138.

\section{NOTAS}

${ }^{1}$ Ver entre otros los trabajos de los colegas Eucidio Pimenta Arruda, 2011, 2013; Regina Miranda, 2013; Ernesta Zamboni y Fátima Díaz Sabino (2014), Angelo Serpa, 2011; Lamas, 
2012; Inés Dussel, 2006, 2010, 2011; Silvia Finocchio, 2014; Marisa Masone, 2014; Gisella Andrade, 2014; Roxana Morduchowicz, 2008, 2014; Eduardo Devoto, 2013; Virginia Cuesta y Elisa Marchese, 2013; Nelly Richard, 2006; María Fernández Batista, 2014; Viviana Zenobi, 2013; Igor Barrenetxea, 2013, entre otros.

${ }^{2}$ Indagamos en diferentes ciudades de la provincia de Río Negro, situadas en las zonas del valle, atlántica y cordillerana; trabajamos en Cipolletti, una ciudad de 90 mil habitantes; en San Antonio, localidad de 30 mil habitantes, y en Bariloche, una urbe de 108 mil habitantes. En la provincia de Neuquén trabajamos en la ciudad capital, que tiene 300 mil habitantes. En variedad de contextos educativos, en los cuatro niveles de enseñanza: infantil, elemental, media y superior. Con pluralidad de propuestas curriculares reguladas, sean estas provinciales o institucionales. Con diversidad de perspectivas para pensar los contenidos, las modalidades de enseñanza y los artefactos culturales.

${ }^{3}$ Esas experiencias se tratan en los siguientes artículos del presente dossier: "La cultura digital en la enseñanza de la historia y las ciencias sociales. Voces del profesorado encuestado y entrevistado en una investigación"; "Formación docente inicial y cultura digital"; "La cultura digital en la enseñanza y aprendizaje de la historia en el nivel medio"; "La enseñanza de las Ciencias Sociales en contextos de digitalización desde el trabajo participativo y colaborativo" y "Ciencias sociales en la educación infantil en entornos digitales. Experiencias del profesorado".

Artigo recebido em 8 de abril de 2016. Aprovado em 1 de junho de 2016. 